\title{
Secondary Metabolites from Streptomyces sp CSDX076 for the First Time
}

\author{
SY Qian ${ }^{1}$, MY Shao ${ }^{1}, \mathrm{YZ} \mathrm{Li}^{2}$, GG Cheng ${ }^{2}$, CW Yue ${ }^{1}$
}

\begin{abstract}
Objective: To investigate the secondary metabolites from the cultures of Streptomyces sp CSDX076.

Methods: The compounds were isolated using column chromatography and RP-18 mediumpressure liquid chromatography. Their structures were elucidated by one-dimensional and two-dimensional nuclear magnetic resonance spectroscopic methods in combination with mass spectrometry experiments.

Results: Four compounds were isolated from the cultures of Streptomyces sp CSDX076 and identified as aurantiamide benzoate, deoxytryptoquivaline, 2-acetyl-3,5-dihydroxyl-benzene acetic acid, and 2-acetyl-3,5-dihydroxyl-benzene ester.

Conclusion: It was the first time that the four isolated compounds were obtained from the Streptomyces genus.
\end{abstract}

Keywords: Isolation and identification, secondary metabolites, Streptomyces sp CSDX076

\section{Metabolitos secundarios de Streptomyces SP CSDX076 por primera vez SY Qian ${ }^{1}$, MY Shao ${ }^{1}, \mathrm{YZ} \mathrm{Li}^{2}$, GG Cheng ${ }^{2}$, CW Yue ${ }^{1}$}

\begin{abstract}
RESUMEN
Objetivo: Investigar los metabolitos secundarios de los cultivos de Streptomyces sp CSDX076. Métodos: Los compuestos fueron aislados usando la cromatografia de columna y cromatografía líquida RP-18 de presión media. Sus estructuras fueron dilucidadas mediante métodos espectroscópicos de resonancia magnética nuclear unidimensional y bidimensional, combinados con experimentos de espectrometría de masa.

Resultados: Cuatro compuestos de culturas de Streptomyces sp CSDX076 fueron aislados e identificados como benzoato de aurantiamida, deoxitriptoquivalina, ácido acético 2-acetil3,5-dihidroxil-benzeno, y éster 2-acetil-3,5-dihidroxil-benzeno.

Conclusión: Fue la primera vez que los cuatro compuestos aislados se obtuvieron del género Streptomyces.
\end{abstract}

Palabras clave: Aislamiento e identificación, metabolitos secundarios, Streptomyces sp CSDX076

From: ${ }^{1}$ Guizhou Key Laboratory of Microbial Resource and Drug Development, Zunyi Medical University, Zunyi 563000, Guizhou, People's Republic of China and ${ }^{2}$ Yunnan Institute of Food Safety, Kunming University of Science and Technology, Kunming 650500, Yunnan, People's Republic of China.
Correspondence: Professor CW Yue, Guizhou Key Laboratory of Microbial Resource and Drug Development, Zunyi Medical University, Zunyi 563000, Guizhou, People's Republic of China. Email: changwuyue@hotmail.com 


\section{INTRODUCTION}

The secondary metabolites (1-6) of Streptomyces played an important role in natural products which have attracted great attention of researchers due to their complicated structures and potential biological activities. Previously reported chemical investigations of the genus Streptomyces include the antifungal hygrolidin (7), cytotoxic elmonin (8), antibacterial angumycinone C (9) and antitumour streptonoate (10). Additionally, it had been implied that the genus Streptomyces was a good source of antibiotic (11-13). In our previous research, we conducted the isolation, and activity screening of the strains from the soil at different altitudes in Chishuidanxia city and Fanjinshan mountain, Guizhou Province, People's Republic of China (PRC). Nine activity strains of the Streptomyces genus were established. Phytochemistry of Streptomyces $s p$ FJS31-2 resulted in a new antibacterial compound, Zunyimycin A (14). In an ongoing research for bioactive secondary metabolites, secondary metabolites of Streptomyces CSXD076 were investigated. Four compounds were isolated and identified as aurantiamide benzoate (1), deoxytryptoquivaline (2), 2-acetyl-3,5-dihydroxyl-benzene acetic acid (3) and 2-acetyl-3,5-dihydroxyl-benzene ester (4). These compounds were reported from this genus for the first time. This paper reports the isolation, and structural elucidation of these compounds.

\section{MATERIALS AND METHODS}

\section{General experimental procedures}

High-resolution electrospray ionisation mass spectrometry (HRESIMS) data were obtained on a Waters Xevo G2 QTOF mass spectrometer with an ACQUITY UPLC BEH C-18 column $(2.1 \mathrm{~mm} \times 50 \mathrm{~mm}, 1.7 \mu \mathrm{m})$. Nuclear magnetic resonance (NMR) spectra were recorded on a Bruker AV 500 NMR spectrometer with tetramethylsilane as an internal standard. The concentration was performed on an EYELA N-1100S-W rotary evaporator. Silica gel (200-300 mesh) for column chromatography and GF254 for thin layer chromatography (TLC) were obtained from Qingdao Marine Chemical Factory, Qingdao, PRC, and sprayed with Dragdorff's reagent. Rp-C18 silica gel (20-45 $\mu \mathrm{m})$ was bought from Fuji Chemical Ltd. Fractions were monitored by TLC (GF 254, Qingdao Haiyang Chemical Co, Ltd, Qingdao, PRC), and spots were visualized by heating after spraying with $5 \% \mathrm{H}_{2} \mathrm{SO}_{4}$ in ethanol. Medium-pressure liquid chromatography (MPLC) was carried out on a Büchi pump system coupled with C18 silica gel-packed glass columns $(15 \times 230 \mathrm{~mm}$ and $26 \times 460 \mathrm{~mm})$.

\section{Materials}

The strain was isolated from the soil of Chishuidanxia city, PRC, and identified as a Streptomyces sp CSDX076 based on a $16 \mathrm{~S}$ ribosomal ribonucleic acid gene analysis. The strain was preserved at China Center for Type Culture Collection (CCTCC no. M2014241), Wuhan University, PRC.

\section{Fermentation, extraction and isolation}

A stock culture of Streptomyces sp CSDX076 strain was maintained at $4^{\circ} \mathrm{C}$ on GYM agar slant consisting of glucose $4 \mathrm{~g}$, malt extract $4 \mathrm{~g}$, yeast extract $10 \mathrm{~g}$, calcium carbonate $2 \mathrm{~g}$ and microelement mixed liquid $0.5 \mathrm{ml}$ in 1 $\mathrm{L}$ distilled water ( $\mathrm{pH} 8.0$ ). The stock culture was inoculated into a $500 \mathrm{ml}$ Erlenmeyer flask containing $200 \mathrm{ml}$ of seed medium which was the same as above without agar. The flask culture was incubated on a rotary shake (160 rpm) for 72 hours. Two hundred milliliters of the flask culture was transferred to a $5000 \mathrm{ml}$ Erlenmeyer flask containing $1000 \mathrm{ml}$ of the producing medium, which contained the same ingredients as the seed medium. The formation was carried out at $28^{\circ} \mathrm{C}$ for 196 hours on a rotary shaker (160 rpm).

The whole fermented cultures (70 L) were extracted with ethyl acetate two times at room temperature. The solvent was evaporated in vacuo to give a crude extract (17.8 g). The extract was subjected to a silica gel column eluting with $\mathrm{CHCl}_{3}$-acetone in gradient (30:1 to $1: 2$ ) to obtain eight fractions (Fractions 1-8). Fraction 3 (2.82 g) was chromatographed by MPLC eluted with methanol-water $(30-80 \%)$ to give six fractions (Fractions 3-1 to 3-6). Fraction 3-2 (200 mg) was chromatographed on a silica gel eluted with petroleum ether-acetone (4:1 to $2: 1)$ to give 1 ( $40 \mathrm{mg}$ ). Fraction 3-1 (1.0 g) was chromatographed on a RP-18 silica gel eluted with methanol-water (20-50\%) to give $2(348 \mathrm{mg}$ ) and 3 (46 mg). Fraction 3-6 was chromatographed on a silica gel eluted chloroform-acetone (10:1 to 4:1) to give 4 (20 mg).

\section{RESULTS}

Compound 1 (Figure) was obtained as a white amorphous powder. Its molecular formula was established as $\mathrm{C}_{32} \mathrm{H}_{30} \mathrm{~N}_{2} \mathrm{O}_{4}$ by HRESIMS data $(\mathrm{m} / \mathrm{z} 529.2106[\mathrm{M}+$ $\mathrm{Na}]^{+}$), indicating 19 degrees of unsaturation. In the ${ }^{1} \mathrm{H}$ NMR spectrum, the aromatic proton signals at $7.70(2 \mathrm{H}$, $\mathrm{dd}, J=8.5,1.5 \mathrm{~Hz}), 7.66(2 \mathrm{H}, \mathrm{dd}, J=8.5,1.5 \mathrm{~Hz}), 7.50$ 

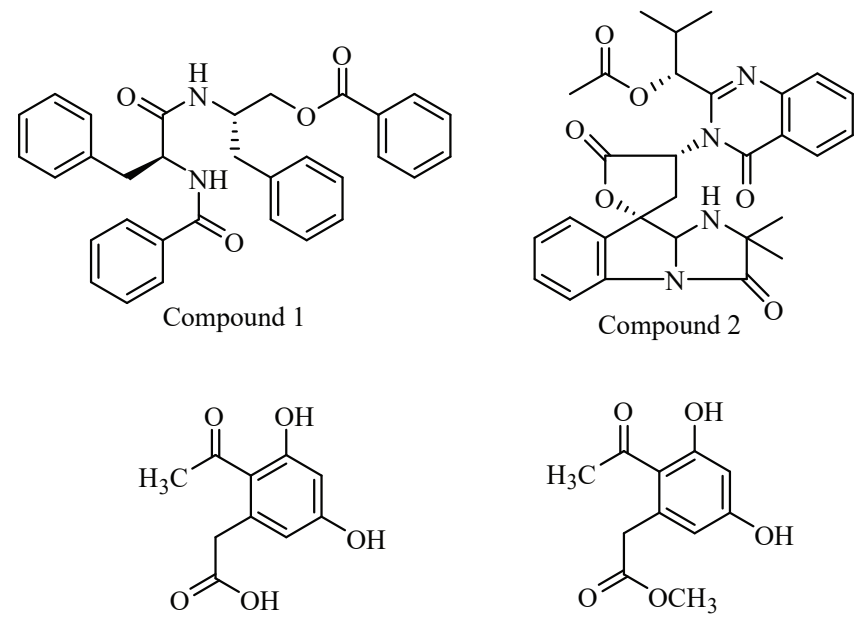

Compound 3

Figure: The structures of compounds 1-4.

$(1 \mathrm{H}, \mathrm{t}, J=7.4 \mathrm{~Hz})$ and $7.21-7.52(15 \mathrm{H}, \mathrm{m}, \mathrm{Ar}-\mathrm{H}) \mathrm{sug}-$ gested the presence of four benzene rings. Two amide $\mathrm{NH}$ proton was also observed at $6.68(1 \mathrm{H}, \mathrm{d}, J=8.5$ $\mathrm{Hz}, \mathrm{H}-3)$ and $6.59(1 \mathrm{H}, \mathrm{d}, J=6.5 \mathrm{~Hz}, \mathrm{H}-6)$. The ${ }^{13} \mathrm{C}$ NMR and distortionless enhancement by polarization transfer (DEPT) spectra of compound 1 displayed 32 carbon resonances ascribable to three methylenes, 22 methines, two carbonyls and five quaternary carbons. Compared to the literature (15), the ${ }^{1} \mathrm{H}$ and ${ }^{13} \mathrm{C}$ NMR data were similar to those of aurantiamide benzoate. As a result, compound 1 was determined to be aurantiamide benzoate.

Compound 2 was obtained as a white powder. Its ${ }^{1} \mathrm{H}$ NMR spectrum displayed five methyl groups $\left[\delta_{\mathrm{H}} 2.13\right.$ (3H, s, H-14), 1.46 (3H, s, H-34), $1.43(3 \mathrm{H}, \mathrm{s}, \mathrm{H}-35)$, $1.21(3 \mathrm{H}, \mathrm{d}, J=6.6 \mathrm{~Hz}, \mathrm{H}-33)$ and $1.01(3 \mathrm{H}, \mathrm{d}, J=6.8$ $\mathrm{Hz}, \mathrm{H}-31)]$, eight aromatic proton signals $\left[\delta_{\mathrm{H}} 8.21(1 \mathrm{H}\right.$, $\mathrm{dd}, J=8.0,1.0 \mathrm{~Hz}, \mathrm{H}-6), 7.89$ (1H, ddd, $J=8.5,7.2,1.5$ $\mathrm{Hz}, \mathrm{H}-4), 7.84(1 \mathrm{H}, \mathrm{d}, J=7.6 \mathrm{~Hz}, \mathrm{H}-5), 7.75(1 \mathrm{H}, \mathrm{d}, J$ $=7.9 \mathrm{~Hz}, \mathrm{H}-3), 7.60(1 \mathrm{H}, \mathrm{m}, \mathrm{H}-11), 7.55(1 \mathrm{H}, \mathrm{d}, J=7.5$ $\mathrm{Hz}, \mathrm{H}-19), 7.50(1 \mathrm{H}, \mathrm{td}, J=7.7,1.0 \mathrm{~Hz}, \mathrm{H}-20)$ and 7.30 $(1 \mathrm{H}, \mathrm{td}, J=7.6,1.1 \mathrm{~Hz}, \mathrm{H}-22)]$. The ${ }^{13} \mathrm{CNMR}$ data and DEPT spectrum indicated that compound 2 possessed 29 carbons, including five methyls, one methylene, 12 methines and 11 quaternary carbons. The signal at $\delta_{\mathrm{C}}$ $172.2(\mathrm{~s}, \mathrm{C}-13)$ and $\delta_{\mathrm{H}} 2.13(3 \mathrm{H}, \mathrm{s}, \mathrm{H}-14)$ revealed the existence of an ester group. The signals at $\delta_{\mathrm{H}} 1.21(3 \mathrm{H}$, $\mathrm{d}, J=6.6 \mathrm{~Hz}, \mathrm{H}-33), 1.01(3 \mathrm{H}, \mathrm{d}, J=6.8 \mathrm{~Hz}, \mathrm{H}-31)$ and $\delta_{\mathrm{C}} 33.7(\mathrm{~d}, \mathrm{C}-32)$ illustrated the presence of one isopropyl group. According to the literature (16), compound 2 was the same as deoxytryptoquivaline. Thus, compound 2 was confirmed to be deoxytryptoquivaline.
Compound 3 was obtained as a white amorphous powder. The ${ }^{13} \mathrm{C}$ and DEPT spectrum of this compound displayed signals for 19 carbons, including one methyl group, one methylene, two methines and six quaternary carbons. According to the ${ }^{1} \mathrm{H}$ NMR data combining with ${ }^{13} \mathrm{C}$ NMR data, the signal at $\delta_{\mathrm{H}} 6.26(1 \mathrm{H}, \mathrm{d}, J=2.3 \mathrm{~Hz}, \mathrm{H}-8)$ and $6.19(\mathrm{H}, \mathrm{d}, J$ $=2.3 \mathrm{~Hz}, \mathrm{H}-6)$ suggested one tetra-substituted benzene ring. The resonances at $\delta_{\mathrm{H}} 2.51(3 \mathrm{H}, \mathrm{s})$ and $\delta_{\mathrm{C}}$ 206.2 could be assigned to the acetyl group. Except for the above information, compound 3 contained one carboxy group. According to above information, compound 3 of one-dimensional NMR data was the same as 2-acetyl-3,5-dihydroxyl-benzene acetic acid, compared with the reported data (17).

Compound 4 was isolated as a white amorphous powder. The one-dimensional NMR data were similar to those of compound 3 except for the presence of the signal $\delta_{\mathrm{H}} 3.64(3 \mathrm{H}, \mathrm{s})$ and $\delta_{\mathrm{C}} 52.3\left(\mathrm{q},-\mathrm{OCH}_{3}\right)$, indicating that the carboxylic group of compound 3 was substituted by methyl ester group of compound 4 . Therefore, compound 4 was confirmed as 2-acetyl-3,5-dihydroxylbenzene ester (18).

\section{DISCUSSION}

The strain of Streptomyces sp CSDX076 was isolated from the soil of Chishuidanxia city, PRC. A chemical study was performed and resulted in the isolation of four compounds, aurantiamide benzoate (1), deoxytryptoquivaline (2), 2-acetyl-3,5-dihydroxyl-benzene acetic acid (3) and 2-acetyl-3,5-dihydroxyl-benzene ester (4), by separation methods and their structural elucidation on the basis of NMR and mass spectrometry. These compounds were obtained for the first time from Streptomyces genus by separation methods and their structural elucidation on the basis of NMR and mass spectrometry. This research provided a basis for further development of the constituents of the Streptomyces genus.

\section{ACKNOWLEDGEMENTS}

This work was supported by the Natural Science Foundation of PRC (numbers 31160004 and 31460006 ) and the Master's Foundation of Zunyi Medical University (number F-757). We acknowledge the State Key Laboratory of Microbial Resource, Institute of Microbiology, Chinese Academy of Science, for measuring the infrared, NMR and mass spectra. 


\section{REFERENCES}

1. Bae M, Kim H, Moon K, Nam SJ, Shin J, Oh KB et al. Mohangamides $\mathrm{A}$ and $\mathrm{B}$, new dilactone-tethered pseudo-dImeric peptides inhibiting Candial albicans isocitrate lyase. Org Lett 2015; 17: 712-5.

2. Liu DZ, Liang BW, Li X. Two new pyrrolosequiterpenes produced by a streptomyces species. Chem Biodivers 2015; 12: 153-6.

3. Guo K, Fang T, Wang J, Wu AA, Jiang J, Wu X et al. Two new spirooxindole alkaloids from rhizosphere strain Streptomyces sp xzqh-9. Bioorg Med Chem Lett 2014; 24: 4995-8.

4. Yang XY, Peng TF, Yang YB, Ding ZT. Antimicrobial and antioxidant activity of a new benzamide from endophytic Sreptomces sp YIM67086. Nat Prod Res 2015; 29: 331-5.

5. Lacret R, Oves-Costales D, Gómez C, Díaz C, de la Cruz M, PérezVictoria $\mathrm{I}$ et al. New ikarugamycin derivatives with antifungal and antibacterial properties from Streptomyces zhaozhouensis. Mar Drugs 2015; 13: 128-40.

6. Jiang ZK, Guo L, Chen C, Liu SW, Zhang L, Dai SJ et al. Xiakemycin A, a novel pyranonaphthoquinone antibiotic, produced by the Streptomyces sp CC8-201 from the soil of a karst cave. J Antibiot 2015; 68: 771-4.

7. Yu ZY, Wang L, Yang J, Zhang F, Sun Y, Yu MM et al. A new qantifungal macrolide from Streptomyces sp KIB-H869 and structure revision of halichomycin. Tetrahedron Lett 2016; 57: 1375-8.

8. Tsukahara K, Toume K, Ishikawa MS, Ishibashi M. Novel cytotoxic isobenzofuran derivatives from Streptomyces sp IFM11490. Tetrahedron Lett 2015; 56: 6345-7.

9. Su HN, Shao HW, Zhang KQ, Li GH. Antibacterial metabolites from the actinomycetes Streptomyces sp P294. J Micobiol 2016; 54: 131-5.
10. Noomnual S, Thasana N, Sungkearee P, Mongkolsuk S, Loprasert S. Streptanoate, a new anticancer butanuote from Streptomyces sp DC3. J Antibiot 2015; 69: 124-7.

11. Lü YH, Shao MY, Wang YY, Qian S, Wang M, Wang Y et al. Zunyimycins $\mathrm{B}$ and $\mathrm{C}$, new chloroanthrabenzoxocinones antibiotics against methicillin-resistant Staphylococcus aureus and Enterococci from Streptomyces sp FJS31-2. Molecules 2017; 22: 251-9.

12. Cui Z, Wang XC, Koppermann S, Thorson JS, Ducho C, van Lanen SG. Antibacterial muraymycins from mutant strains of Streptomyces sp NRRL 30471. J Nat Prod 2018; 81: 942-8.

13. Lu C, Li JM, Qi H, Zhang H, Zhang J, Xiang WS et al. Two new lankacidin-related metabolites from Streptomyces sp HS-NF-1178. J Antibiot (Tokyo) 2018: 71: 397-401.

14. Lü YH, Yue CW, Shao MY, Qian SY, Liu N, Bao Y et al. Molecular genetic characterization of an anthrabenzoxocinones gene cluster in Streptomyces Sp FJS31-2 for the biosynthesis of BE-24566B and Zunyimycin Ale. Molecules 2016; 21: 1-9.

15. Chen JM, Wei LB, Zhang Y, Ye WC, Zhou GX. Chemical constituents in petroleum ether fraction of Nerviliae fordii. J Jian Univ 2013; 34: 324-7.

16. George B, Kin CK, Brunhilde K, James MT. Four new mycotoxins of Aspergillus clavatus related to Tryptoquivaline. J Org Chem 1977; 42: 244-6.

17. Li LL, Chen JP, Kong LY. Chemical constituents of Monascus anka. Chin Pharmacol J 2006; 41: 1131-3.

18. Varma GB, Fatope MO, Marwah RG, Deadman ME, Al-Rawahi K. Production of phenylacetic acid derivatives and 4-epiradicinol in culture by Curvularia lunata. Phytochemistry 2006; 17: 1925-30. 